\title{
Female labour market outcomes and the impact of maternity leave policies
}

\author{
Hamish Low ${ }^{1,2}$ and Virginia Sánchez-Marcos ${ }^{3 *}$
}

\author{
*Correspondence: \\ sanchezv@unican.es \\ 3 Departamento de Economía, \\ Universidad de Cantabria Avda. de \\ los Castros s/n, 39005 Santander, \\ Spain \\ Full list of author information is \\ available at the end of the article
}

\begin{abstract}
This paper shows how family policies aimed at reconciling the pressures of family and work generate substantial variation in labour market outcomes across developed countries. We use a life-cycle model of female labour supply and savings behaviour, calibrated to the US economy, to assess the effect of introducing to the US a maternity leave policy similar to Scandinavian-type policies. We focus on the impact on gender differences in participation and in wages. We distinguish between the effect of the job protection offered by maternity leave and the effect of income replacement. Job protection leads to substantial increases in participation of mothers with children under 6 , but with little long term effects. The effects on wages are minimal, with negative selection effects offsetting the reduced human capital depreciation. Income replacement has a limited impact on participation or wages.
\end{abstract}

JEL codes: J13; J18; J22

Keywords: Labor supply; Maternal leave; Returns to work

\section{Introduction}

Across the OECD, there remain substantial gender wage gaps (averaging $15.8 \%$ in 2009) as well as substantial gaps in employment rates between men and women (averaging $20.6 \%$ in 2009). The size of these gaps varies significantly across countries, with much of these differences due to differences in the behaviour of mothers in the years following childbirth. The aim of this paper is to understand the role of maternity leave policies in explaining these differences across different countries.

Maternity leave policies are now widespread and diverse across the OECD. ${ }^{1}$ Policies typically have two key components: first, providing job protection through the option to return to the same job after a period of leave, and second, providing income replacement during the period of leave for those who return to work. The first of these policies helps protect female wages through maternity leave, while the second helps to smooth consumption. Both effects will impact the gender wage gap and the gender employment gap directly and through selection effects.

The direct effects were highlighted by Waldfogel (1998a), who argued that maternity leave would increase the retention of woman during the period of child-rearing. This in turn would increase their work experience and job tenure and thereby allowing them to maintain good job matches and higher wages. ${ }^{2}$ Offsetting this direct effect narrowing the wage and employment gender gaps are several selection mechanisms. First, maternity

(c) 2015 Low and Sánchez-Marcos. This is an Open Access article distributed under the terms of the Creative Commons Attribution License (http://creativecommons.org/licenses/by/4.0), which permits unrestricted use, distribution, and reproduction in any medium, provided the original work is properly credited. 
leave may induce a return to work for those women who would otherwise have left the labour market altogether for a lengthy period of time. ${ }^{3}$ In addition, as argued by Ruhm (1998), women that would not otherwise participate in the labour market may choose to be active prior to childbirth in order to subsequently qualify for maternity leave benefits. This induced extra participation may be by women who are less productive and with lower wages, worsening the gender wage gap. These selection effects on wages may be worsened by women who do take leave, choosing to take longer periods out of work during which they do not accumulate human capital. While these selection effects may explain why negative wage effects occur, they do not imply that the policy has a negative effect on welfare: the increased activity by less productive women is a positive outcome because it shows that the policy is increasing labour market engagement among the excluded. For these women, the welfare effects are likely to be substantial and positive. A further consideration is that employers may pass the cost of maternity leave policies onto mothers by lowering their wages if maternity leave is not provided as a tax-funded social insurance benefit. Job protection policies replace private agreements and therefore can increase welfare. However, our focus is on showing the effects in particular dimensions rather than discussing welfare.

This paper uses a quantitative life-cycle model to evaluate the direct impact and the selection effects caused by the two strands of maternity leave policies: job protection and income replacement. We focus on the partial equilibrium effects. We model the savings and female labour participation decisions made by households when human capital depreciates during spells out of the labour force. The importance of saving and borrowing is that it reduces the importance of the income replacement role of maternity leave. The inclusion of saving and borrowing is the key difference in our framework, compared to others such as Erosa et al. (2010) and Lalive et al. (2014). The benefit of the option of returning to the former job arises because human capital is protected by returning to the former job. This assumption is based on the premise that a share of human capital is job specific and that this does not depreciate in a short spell away from that job. We calibrate the model economy to data from the US on mothers' participation rates at different child ages, on observed life-cycle wage growth for women, on the wage gender gap and on the fraction of the motherhood wage penalty that can be attributed to labour market interruptions in the US economy.

Our life-cycle framework allows us to explore the counter-factual effects on mothers in the US of changes to maternity leave to mimic the type of policy observed in Scandinavia. The key aspects of this counter-factual are the introduction of income substitution through maternity payments and the introduction of greater job protection. We contrast the short and long-run effects of these policies on female participation and the gender participation gap, as well as disentangle the direct effect from the selection effect on wages.

Our main result is that there is a substantial effect of rights to paid maternity leave on mothers' employment rates, in particular of mothers of children aged 0 to 2 . This is as a consequence of women being more likely to participate in the workforce in order to be eligible for maternity leave and of women being more likely to reenter the labour force after childbearing due to the protection of human capital. ${ }^{4}$ The effect is also substantial on the employment rate of mothers of children aged 3 to 5 . We show that it is the job-protection aspect of the policy what drives this increase in participation, whereas the 
income replacement aspect reduces participation of this group of mothers through an income effect. However, by the time children are aged 6, there is little difference in the employment rate as maternity leave changes. In terms of wages, the direct benefit of job protection helps to maintain wages of those who chose to exit at child arrival in the benchmark. However, this direct benefit is offset by two other effects: first, for women who remain employed but who take leave, human capital accumulation is less and so wages are lower. Second, there is a negative selection effect: new participants are less productive (conditioning on human capital) than existing participants. In aggregate, these latter two effects lead to a woresening of the gender wage gap.

The rest of the paper is organised as follows. Section 2 discusses the literature and the reduced form evidence. Section 3 describes the key facts about participation and wages around child birth. In section 4 we present the model economy we use for the analysis and show the calibration to the US economy. In section 5 we simulate the effects of introducing more generous maternity leave, both in terms of job protection and in terms of income replacement. Finally, section 6 concludes.

\section{Literature}

The existing empirical literature addressing the effects of maternity leave uses quasiexperimental evidence, cross-sectional evidence and quantitative macro evidence. The literature is focused on three main questions: first, what are the overall effects of maternity leave on participation and wages following childbirth; second, are these effects driven by the job protection part of maternity leave or the income replacement part; and finally, what are the long term effects compared to the effects immediately after childbirth. Our paper addresses all three questions in a unified model and then shows the effects of moving from a US minimal maternity leave provision to a more generous provision similar to policies observed in Scandinavia.

There is a large literature on the overall effects of maternity leave on wages and participation. Waldfogel et al. (1999) find that maternity leave increases the likelihood that a woman will return to her employer after childbirth in the US, Britain and Japan. Furthermore, there is evidence both in the US and Britain (Waldfogel 1998a) that women who use maternity leave to maintain employment continuously over childbirth have higher pay subsequently than those who do not. Similarly, Ruhm (1998) finds that in nine European countries, maternity leave legislation raises the female employment rate. However, there is an offsetting effect on observed wages: the right to 40 weeks of job-protected paid leave is predicted to reduce hourly wages by $2.7 \%$ due to negative selection (Ruhm 1998). ${ }^{5}$

Albrecht et al. (1999) use Swedish data and show that time out (due to parental leave, unemployment or other reasons) has a significant negative effect on subsequent wages, but that the effect differs by gender, being stronger for men. Gupta et al. (2008) find evidence of family-friendly policies in Nordic countries, such as long paid maternity leave, having negative effects on women's wages. Gupta et al. (2006) find that between 1983 and 1995 the wage gender gap widened in Denmark, whereas the opposite was observed in the US. Ejrnæs and Kunze (2013) use register data on West Germany, and they exploit the expansionary family policy during the late 1980s and 1990s for identification: wages of mothers drop by $3-5.7 \%$ per year of leave. They also find negative selection back to full-time work after childbirth. Nielsen et al. (2004) show that this negative selection operates partly through the sector that women work in, with those in the non-family friendly 
sector suffering very large penalties, and so there is self-selection into family friendly sectors where wages are lower. The negative effects of maternity leave on wages offset some of the benefits through increased participation. Our simulation analysis can provide a framework for understanding some of these wage dynamics following changes in maternity leave policies policy.

There is a smaller literature addressing the mechanism through which maternity leave has an effect. This literature attempts to distinguish between the job protection and income replacement effects. Schönberg and Ludsteck (2011) analyze the impact of five major expansions in maternity leave coverage in Germany. These expansions differed in the extent that job protection changed compared to income replacement. When the expansion was to both aspects, short-run employment falls, but there is only a small effect on women's employment rates and labour market income 6 years after childbirth. By contrast, when income replacement was extended but not job protection, employment fell both in the short run and 6 years later. In the US, the Family and Medical Leave Act of $1992^{6}$ offered only job protection for 12 weeks, and this was found to have limited impacts on the length of leave (Baum 2003; Han and Waldfogel 2003; Waldfogel 1999; Klerman and Leibowitz 1999), and it did not affect post-pregnancy employment or wages (Klerman and Leibowitz 1999, Baum 2003 and Waldfogel 1999). In Canada, Baker and Milligan (2008) focused on identifying the impact of extensions of job-protected leave by exploiting variations in provincial dates. As in the US, this research found that short unpaid mandates (12 to 18 weeks) had no impact on mother's participation, while later expansions in 1990/1991 and 2000/2001 had larger impacts on participation during the period of eligibility for leave. Rossin-Slater et al. (2011) estimate the effects of California's Paid Family Leave (PFL) programme, which combined both elements of maternity leave, and find that the overall use of maternity leave increased from around three to 6 or 7 weeks for the typical new mother, with particularly large increases for less advantaged groups who had relatively low levels of baseline use. ${ }^{7}$ After the maternity leave period, the PFL programme increased the usual weekly hours worked of employed mothers of children aged 1 to 3 by between $6 \%$ and $9 \%$. In a structural model of job search in Austria, Lalive et al. (2014) and Lalive and Zweimüller (2009) focus on behaviour after childbirth and find an important interaction between the two aspects of the policy: longer cash benefits lead to a significant delay in return-to-work in the period that is job-protected. Further, they find prolonged maternity leave absences do not hurt mothers' labour market outcomes in the medium run.

These studies seem to suggest that the main impact of maternity leave is coming through the income replacement aspect rather than job protection. This is in contrast to our findings. Part of the reason for our different conclusion is the inclusion of saving and borrowing in our model. Saving and borrowing gives households the ability to smooth consumption through periods out of the labour force without relying on external income replacement. This is reinforced by the joint modelling of male and female earnings: male earnings also provide income to maintain consumption during periods out of the labour force to look after children, and this reduces the need for income replacement through maternity leave policies. This modelling of households as being risk-averse but able to borrow and save against periods of anticipated and unanticipated low income is the key difference in our framework, compared to Erosa et al. (2010) and Lalive et al. (2014). 


\section{Empirical facts}

In this section we provide the key facts that motivate the paper. First, we describe childbirth related policies in the countries of interest. Second, we describe female labour market performance in terms of participation and wages. Statistics provided in this section correspond to the period 2007-2009, and in section 4.2 we use them in order to map out the model economy to the US economy.

We start by providing a description of the maternity policies in the US and the Scandinavian countries. ${ }^{8}$ Maternity leave policies can be classified by the length of time that a woman's job is protected, by the length of time she receives income replacement and by the generosity of that income replacement. In the US, there are 12 weeks of job protection by law, but it is unpaid. By contrast, in Sweden, job protection from maternity and parental leave is for a total of 70 weeks, with 10 weeks at a replacement rate of $80 \%$ and 60 weeks at a 64\% replacement rate. Similarly, in Norway, there are 97 weeks of job protection, with 9 weeks at a replacement rate of $100 \%$ and 88 weeks at 33\%. Finally, in Denmark, there are 18 weeks maternity leave and 32 weeks parental leave, with both at a $53 \%$ rate of allowance. We calculate the equivalent 1-year duration maternity leave as the replacement rate that would be received if the parental leave was all taken by the mother who was not working for 1 full year. We use this 1 year equivalent to create a counter-factual maternity leave policy with a $69 \%$ replacement rate lasting for 1 year, which is similar in spirit to those in Scandinavia. ${ }^{9}$ There may additionally be private maternity arrangements, particularly in the US where there is such limited state provision. The OECD (2012) reports that $45 \%$ of mothers in the US used paid maternity leave despite the lack of state arrangments, but the duration of leave is very short, with only $20 \%$ of mothers still on leave after 12 weeks.

Alongside these differences in maternity leave policies are differences in labour market outcomes for women. We focus on two key facts taken from the OECD Family Database, which uses the EU-Labour Force Survey and the US-Current Population Survey. We contrast the US and Scandinavia. First, we show there are differences in labour supply at child-bearing ages. Second, we show that the wage gender gap differs substantially.

Fact 1: Women's employment is substantially higher across Scandinavia than in the US. In the first panel of Table 1, we report rates of employment for mothers, distinguishing by the age of their children. ${ }^{10}$ For mothers of children age 2 or less, employment is $72 \%$ across Scandinavia, but only $54 \%$ in the US. ${ }^{11}$ A fraction of those in employment in Scandinavia are not actually working: being on maternity leave is classified as being employed. We therefore split this group into what fraction of women are in work compared to what fraction are on leave. The fraction of mothers actually in work is only $48 \%$. There is no such meaningful distinction to make for the US, where being in employment means being

Table 1 Employment rates and wages

\begin{tabular}{lcc}
\hline & Scandinavian & US \\
\hline Mothers of children $\leq 2$ & 0.72 & 0.54 \\
Mothers with children $\leq 2$ in work & 0.48 & - \\
Mothers with children $\leq 2$ on leave & 0.24 & - \\
Mothers of children $3-5$ & 0.79 & 0.63 \\
Mothers of children $6-14$ & 0.79 & 0.73 \\
\hline Gross wage gender gap & 0.12 & 0.20 \\
\hline Source: OECD Family Database & &
\end{tabular}


in work. However, the observed difference in employment rates for mothers of children aged 3 to 5 is not affected by their labelling of maternity leave, and yet the gap in the employment rates between countries is still substantial: $79 \%$ in Scandinavia versus $63 \%$ in the US. This gap in employment rates declines as the children age. ${ }^{12}$

Fact 2: The gender wage gap is substantially lower across Scandinavia than in the US. The second panel of Table 1 reports the gross wage gender gap, defined as one minus the median woman's wage relative to males'. For the US the gap is about $20 \%$, whereas across Scandinavia it is only $12 \%$.

Understanding the importance of maternity leave in generating these two differences across the countries is the focus of our model and calibration. However, it is important to consider other potential factors that might generate these differences. First, fertility rates: total fertility rates are very similar in the US (1.93) to the average of the Scandinavian countries (1.95), and so differences in fertility behaviour do not seem to be behind the differences in female labour market outcomes. On the other hand, the average age of mothers at the time of the first child is significantly younger in the US (at age 25) than in Scandinavia (at age 29). Second, average child care costs: for a 2 year old, child care costs about $20 \%$ of average worker earnings in the US, whereas it only costs $7 \%$ of average worker earnings in the Scandinavian countries. ${ }^{13}$ Attanasio et al. (2008) show that reductions in child care costs can have substantial effects on the participation rates of mothers with children younger than 3 , with a $20 \%$ reduction leading to an 18 percentage point increase in participation. Finally, the benefit systems differ across the countries: in the US, the maximum family benefits for each child aged 3 to 12 are about $50 \%$ of those in the Scandinavian countries. ${ }^{14}$

\section{Life-cycle model and calibration}

\subsection{Model}

We present our life-cycle model to include the possibility of maternity leave that provides job protection rights and income replacement. However, the calibration is to the US economy, where there is no mandatory income replacement.

In our model, unitary households maximise expected lifetime utility. The utility function is intertemporally separable, and instantaneous utility depends on household consumption per adult equivalent and the labour supply choice of the woman. We assume that all households have two adults who remain married and that husbands always work and receive earnings that follow a stochastic process. Families differ by whether and when they have children. Children arrive deterministically to the household and do not have a direct effect on utility, but they affect the household by deflating consumption by their adult equivalent and through changing the cost for the woman of going to work.

Each household is assumed to maximise lifetime expected utility,

$$
\max _{c, P} V_{i t}=E_{t} \sum_{s=t}^{T} \beta^{s-t} u\left(c_{s}, P_{s} ; e_{i s}\right),
$$

where $\beta$ is the discount factor, $P_{s}$ is a discrete $\{0,1\}$ female labour supply choice, $c_{s}$ is total household consumption and $e_{i s}$ is the number of adult equivalents in the household that depends on the age of the household head and the household type, $i$. We consider a retirement period after which no one participates in the labour market and the household receives a pension proportional to the husband's earnings after retirement in period 
$T-T_{R} \cdot{ }^{15}$ Children are not included explicitly in the utility function. Since having children is not a choice, we could include an additive term for children in the utility, and that would not change any of the analysis. However, such an additive term would not be identified in an environment where having children is not a choice. The important assumption we are making is that the marginal utility of consumption is affected by children only through the equivalence scale.

The intertemporal budget constraint for a household has the form

$$
A_{t+1}=(1+r)\left(A_{t}+\left(y_{t}^{f}-p g_{i t}\right) P_{t}+b y_{t}^{f}\left(M_{t}^{e} \cdot\left(1-P_{t}\right)\right)+y_{t}^{m}-c_{t}\right)
$$

$A_{t+1}$ are beginning of period assets, $r$ is the fixed interest rate, $g_{i t}$ is the number of child care units needed by a family $i$ of age $t$, and $p$ is the price of each unit of child care. This means that the fixed cost of work depends on the children's age and number. Female earnings are given by $y_{t}^{f}$, and husband earnings are given by $y_{t}^{m}$. In any period, individuals are able to borrow against the minimum income they can guarantee for the rest of their lives. We include a saving and borrowing mechanism because this is a way to smooth the fixed cost of work for mothers who work and a way to smooth consumption for mothers who do not work. On the other hand, we also include a retirement savings motive in our model to have a realistic amount of savings so that the potential role of female labour supply as a private insurance mechanism is not overestimated.

Maternity leave modifies the opportunity set for households in two ways. First, maternity leave offers job protection, which we model as human capital being preserved during the period of maternity leave. This assumption is intended to capture the idea that firms help women returning from maternity leave to stay engaged and, further, that returning to the same job avoids the loss of firm specific human capital. The second benefit of maternity leave is the cash benefit is provided during leave. We set this benefit equal to a fraction $b$ of their previous wage. These two benefits are only available to eligible mothers. In order to be eligible for maternity leave, a woman has to be employed in the period prior to her child's arrival. The variable $M_{t}^{e}$ indicates eligibility: $M_{t}^{e}=1$ if the woman was working in the period prior to childbirth. ${ }^{16}$ Women who are eligible for maternity leave will receive the benefits of maternity leave if they choose not to work in the maternity leave period.

Female earnings in period $t$ are given by

$$
\ln y_{t}^{f}=\ln y_{0}^{f}+\ln h_{t}^{f}+v_{t}^{f},
$$

where $h_{t}^{f}$ is the level of human capital at the start of the period, and $v_{t}^{f}$ is the permanent productivity shock.

Except in periods out of the labour force following childbirth, human capital evolves endogenously with employment decisions in the following way

$$
\ln h_{t+1}^{f}=\ln h_{t}^{f}+\eta_{t} P_{t}-\delta\left(1-P_{t}\right) .
$$

Following childbirth, women can choose to work or not. For those who choose not to work, human capital evolves as

$$
\ln h_{t+1}^{f}=\ln h_{t}^{f}-\delta\left(M_{t}^{e}=0\right)
$$

This shows the job protection benefit of maternity leave: depreciation occurs only if the mother is not working in period $t$ and is not eligible for maternity leave (i.e., was not working prior to childbirth) or if maternity leave is not available. In reality, this depreciation 
comprises both a loss of human capital and a loss of match quality. Leaving a firm causes the destruction of the match and so the decline in wages associated with even a very short period of not working may be substantial. In such a context, the job protection aspect of maternity leave is particularly valuable as it preserves the match quality in an uncertain labour market. Our assumption of a linear depreciation rate may therefore understate the value of job protection.

Depreciation is a permanent loss, but human capital is subject to a lower bound. This means that the marginal loss of human capital associated with a year out of the labour force becomes zero for a sufficiently long unemployment spell. Evidence of wage losses by displaced workers have been reported in the literature by Jacobson et al. (1993) and more recently by Couch and Placzek (2010). ${ }^{17}$ Jacobsen and Levine (1995) document the impact on female earnings of intermittent labour supply. They find evidence that spells out of the labour market have lasting negative effects on mothers, of even 10\% after 11-20 years after the spell. As regards the process of human capital accumulation, we assume, as in Olivetti (2006), that the marginal increase in human capital depends on age.

Men always work, and male earnings are given by

$$
\begin{aligned}
\ln y_{t}^{m} & =\ln y_{0}^{m}+h_{t}^{m}+v_{t}^{m} \\
h_{t}^{m} & =\alpha_{1}^{m} t+\alpha_{2}^{m} t^{2}
\end{aligned}
$$

We further assume that male labour supply is unaffected by maternity leave or by the women's choice about how much to work. ${ }^{18}$

Both female and male earnings, $y_{t}^{f}$ and $y_{t}^{m}$, in the household are subject to permanent shocks, $v_{t}^{f}$ and $v_{t}^{m}$, that are positively correlated. This is the only source of uncertainty that households face. They are assumed to have perfect foresight regarding fertility, child care costs, the process for human capital accumulation and the fact that they will remain married. In particular, we assume

$$
\begin{aligned}
& v_{t}^{f}=v_{t-1}^{f}+\xi_{t}^{f} \\
& v_{t}^{m}=v_{t-1}^{m}+\xi_{t}^{m} \text { where } \xi_{t}=\left(\xi_{t}^{f}, \xi_{t}^{m}\right) \sim N\left(\mu_{\xi}, \sigma_{\xi}^{2}\right) \\
& \mu_{\xi}=\left(-\frac{\sigma_{\xi^{f}}^{2}}{2},-\frac{\sigma_{\xi^{m}}^{2}}{2}\right) \quad \text { and } \quad \sigma_{\xi}^{2}=\left(\begin{array}{cc}
\sigma_{\xi^{f}}^{2} & \rho_{\xi^{f}, \xi^{m}} \\
\rho_{\xi^{f}, \xi^{m}} & \sigma_{\xi^{m}}^{2}
\end{array}\right)
\end{aligned}
$$

We assume that there is no correlation between productivity (male or female wages) and fertility types. ${ }^{19}$

In each period, the value function for a working woman is given by

$$
\begin{aligned}
& V_{i t}^{1}\left(a_{t}, v_{t}^{m}, v_{t}^{f}, h_{t}^{f}, M_{t}^{e}\right)= \\
& \quad \max _{c_{t}}\left\{u\left(c_{t}, P_{t}=1 ; e_{i, t}\right)+\beta E_{t}\left[\max \left\{\begin{array}{c}
V_{i t+1}^{0}\left(a_{t+1}, v_{t+1}^{m}, v_{t+1}^{f}, h_{t+1}^{f}, M_{t+1}^{e}=1\right) \\
V_{i t+1}^{1}\left(a_{t+1}, v_{t+1}^{m}, v_{t+1}^{f}, h_{t+1}^{f}, M_{t+1}^{e}=1\right)
\end{array}\right\}\right]\right\}
\end{aligned}
$$

However, if she chooses not to participate, the value function is given by

$$
\begin{aligned}
& V_{i t}^{0}\left(a_{t}, v_{t}^{m}, v_{t}^{f}, h_{t}^{f}, M_{t}^{e}\right)= \\
& \quad \max _{c_{t}}\left\{u\left(c_{t}, P_{t}=0 ; e_{i, t}\right)+\beta E_{t}\left[\max \left\{\begin{array}{c}
V_{i t+1}^{0}\left(a_{t+1}, v_{t+1}^{m}, v_{t+1}^{f}, h_{t+1}^{f}, M_{t+1}^{e}=0\right) \\
V_{i t+1}^{1}\left(a_{t+1}, v_{t+1}^{m}, v_{t+1}^{f}, h_{t+1}^{f}, M_{t+1}^{e}=0\right)
\end{array}\right\}\right]\right\}
\end{aligned}
$$


The decision of whether or not to participate in period $t$ is determined by comparing these value functions. The participation choice and the consumption choice in $t$ determines the endogenous state variables (assets and human capital) at the start of the next period. The non-concavity in the value function induced by the discrete participation decision is smoothed out by the presence of sufficient uncertainty. We confirm that this holds in the numerical solution of the problem, as discussed in the Appendix 2. The additional state variable, $M_{t}^{e}$, is only used when maternity leave is available, which depends on a child being born that year and on the policy regime being analysed.

\subsection{Calibration}

We calibrate the model with data from the US economy. The calibration is intended to capture the tradeoffs of spells out of the labour market as well as life-cycle wage growth. There are two sets of parameters. The first set is measured directly from the data or taken from previous estimates in the literature. The second set is calibrated matching moments in the data with simulated moments from the model. For these parameters, a key feature of our approach is that for all the statistics that involve female labour market outcomes, we implicitly control the self-selection process that is operative in our model. Both in the data and in the simulations, the women on which the moments are computed are from a selected sample of the population.

\subsubsection{Specification, parameter values and targets}

We use a utility function of the form

$$
u\left(c_{t}, P_{t} ; e_{i t}\right)=\frac{\left(\frac{c_{t}}{e_{i t}}\right)^{1-\gamma}}{1-\gamma}-\psi P_{t}
$$

The number of adult equivalents in the household is given by $e_{i t}$, which depends on the type of household and age. We use the McClements scale, according to which a childless couple is equivalent to 1.67 adults, a couple with one child is equivalent to 1.9 adults if the child is less than 3, to 2 adults if the child is between 3 and 7, 2.07 adults if the child is between 8 and 12 and 2.2 adults if the child is between 13 and 18. As we explain below, we assume that each couple has two children who arrive at a predetermined age and leave at age 18. We allow heterogeneity in the age of first child's arrival by allowing for three types of family: those who do not have kids, those who have kids early in life and, finally, those who have kids later in life. According to the OECD 15\% of women in the US never have a child, and this is what we assume here to be the first group. ${ }^{20}$ For those women that do have a child, the average age is 25 at first birth, and so we assume that $42.5 \%$ of women have their first child at age 24 (we call this group young mothers) and $42.5 \%$ have their first child at 27 (we call this group old mothers). We assume the second child comes 3 years after. ${ }^{21}$ The type of family, $i$, together with age of the child determines the fixed cost of work and the number of adult equivalents in the households.

The child care cost function $g_{i t}$ is calculated from data provided by State Child Care Resource and Referral Network offices for pre-school children. ${ }^{22}$ Average annual full-time child care cost for an infant in a center varies between $\$ 14,009$ in the state of New York (that is about $16 \%$ of state median income for two parent families) and $\$ 4,591$ in the state of Mississippi (7\%). Child care cost for a 4-year-old child is about $20 \%$ cheaper, $\$ 11,585$ in the case of New York and \$3,911 in the case of Mississippi. Given this information on the 
relative cost, depending on age and considering that in our model all women with children have two of them separated by 3 years, we shape $g_{i t}$ such that it captures the evolution of a household's child care cost with the age of the first child for household of type $i$. As we discuss below, we calibrate the price $p$ by matching moments from the model with moments in the data.

All women in our model begin their lives at age 23 with zero assets, and they live for 50 periods. During the last 10 periods, they are retired from the labour market, as is the case for their husbands. We fix the rate of return to savings to equal the average real return on three monthly T-bills at 0.015 , and we assume a discount factor equal to 0.98 . In the utility function, the coefficient of relative risk aversion, $\gamma$, is set to 1.5 , which is consistent with the evidence on the elasticity of intertemporal substitution in the US provided by Attanasio and Weber (1995).

The deterministic component of the male earnings process is consistent with wage growth as reported from the NLSY79. ${ }^{23}$ In particular, we target average annual wage growth of 0.03 from 30 to 39 and of 0.01 from 40 to 46 . This gives a wage growth of 0.04 from 25 to 29 also consistent with NLSY79.

Both the innovations in male earnings and those in female wages are assumed to have a unit root, consistent with the evidence about men found by MaCurdy (1983) and Abowd and Card (1989). The standard deviation of the innovation for a husband's earnings is assumed to be 0.13 . This number is similar to the variances estimated using PSID data by Carroll and Samwick (1997) or Low et al. (2010). There is not much evidence on the variability of female wages and/or earnings. Assuming that the variance of female wages innovations is the same as that of men's earnings, we compute the implied coefficient of variation of female earnings in our simulations, which comes out at 0.64 . This turns out to be very similar to the value of 0.65 reported by Hyslop (2001) for female earnings. ${ }^{24}$ We therefore settled for the value of 0.13 . We assume that the correlation coefficient between the two shocks (for husband and wife) is equal to 0.25 as estimated by Hyslop (2001).

There remain six parameters to be calibrated: the utility cost of working $\psi$; the price of child care $p$; the depreciation rate $\delta$; the initial wage gender gap $y_{0}^{f} / y_{0}^{m}$; and, finally, two parameters of the human capital accumulation function, $\eta_{0}$ for females up until the age of 39 and $\eta_{1}$ for females aged 40 to 60 . We choose six moments in the data to target (see the first panel of Table 2). We select two labour market participation statistics from OECD Family Database: employment rate of childless women, 0.77, and employment rate of mothers of children aged 0 to 2, 0.54 . We also target the 0.2 gross wage gender gap and the female wage growth at different ages as measured from NLSY79. Average female wage growth from 25 to 39 is 0.03 and 0.01 from 40 to 46 . Finally, we align the model to the gross wage motherhood penalty (one minus average wage of mothers relative to average wage of childless women). Budig and England (2001) argue that mothers may earn less than other women because having children causes them to lose human capital, be less productive at work, trade off higher wages for mother-friendly jobs, or be discriminated against by employers. Waldfogel (1998b) finds that for mothers of two children, the wage penalty is about $13.2 \%$ after controlling by education, year, age and race. ${ }^{25}$ However, the gap goes down to $8.1 \%$ once differences in labour market experience are taken into account. ${ }^{26}$ So this implies that $5.1 \%$ of the wage gap with respect to childless women is related to their lower attachment to the labour market, and this is what we target here. ${ }^{27}$ 
Table 2 Calibration

\begin{tabular}{lll}
\hline Targets & Model & Data \\
\hline Childless women employment rate & 0.78 & 0.77 \\
Mothers 0 to 2 employment rate & 0.54 & 0.54 \\
Wage gender gap & 0.20 & 0.20 \\
Female wage growth (aged 25 to 39) & 0.03 & 0.03 \\
Female wage growth (aged 40 to 46) & 0.01 & 0.01 \\
Motherhood wage penalty & 0.06 & 0.05 \\
\hline Parameters & & \\
\hline$\psi$ & 0.003 & \\
$p$ & $29250^{\mathrm{a}}$ & \\
$1-y_{0}^{f} / y_{0}^{m}$ & 0.23 & \\
$\eta_{0}$ & 0.03 & \\
$\eta_{1}$ & 0.005 & 0.63 \\
$\delta$ & 0.04 & 0.73 \\
\hline Other Statistics & Model \\
\hline Mothers 3 to 5 employment rate & 0.70 & 5 \\
Mothers 6 to 14 employment rate & 0.78 & 0.69 \\
Median duration of spells & 6 & \\
Female employment rate & 0.69 & \\
\hline
\end{tabular}

aThis corresponds to $22 \%$ of a two-earner household's mean earnings

In the second panel of Table 2, we report parameter values that are calibrated by solving the model. The calibrated value for the price of child care implies that child care costs paid for an infant is about $22 \%$ of a two-earner household's mean earnings. This is, according to the National Association of Child Care Resource and Referral Agencies, above the cost reported in the least-affordable states of the US (16\%). However, since we do not specify any other time or monetary child-related costs for working mothers, our model requires this relatively high price of child care in order to target the employment rate of mothers of young children. The initial offer wage gender gap is calibrated to 0.23 , so it is higher than the observed gender gap. This is as a result of the positive self-selection of women into the labour market that our model implies. Positive self-selection is consistent with Olivetti and Petrongolo (2008), who find that wage gender gaps across countries are negatively correlated with gender employment gaps due to positive self-selection of women into the labour market. As regards to the value of the depreciation rate of human capital, the calibrated parameter is $4 \%$, which is above the estimates of Mincer and Olfek (1982) of $2 \%$. However, the implied annualized wage loss due to non-participation in our model is $3 \%$. This lower annualized wage loss arises because the impact of depreciation on human capital is constrained by the assumption that human capital cannot fall below its starting value. Furthermore, positive self-selection into the labour market downward bias the observed annualized wage depreciation.

\subsubsection{Other statistics}

In addition to statistics that are used for the calibration, in the third panel in Table 2, we report other labour market statistics that are helpful in assessing the ability of the model to account for female labour supply behaviour. The model captures well the increase in the participation rate as children age as well as average participation rates. Finally, Jacobsen and Levine (1995) find that the median duration of exits in the data is about 5 years, and $85 \%$ of exits are due to family responsibilities. In the simulations median duration of the first exit is 6 years, and it takes place at a median age of 28 and so is related to children's arrival. 
Finally, an important feature of our model economy is wealth accumulation. One of our main points is that access to credit markets affects the value of maternity leave: households can smooth consumption through saving and borrowing. Hence, it is important that our model matches asset profiles. In our benchmark economy, the median ratio of wealth to husband income of households has risen by age 55 to about 5.4 . This is comparable to the numbers in the data reported in Low et al. (2010) if we include private pension wealth and housing wealth. In the simulations, the fraction of households borrowing against future income at the time the first child arrives is $14 \%$. This fraction increases until age 35 , driven by the needs of children, and then decreases from then on as accumulation for retirement begins.

\section{Policy evaluation}

In this section we evaluate the effect of introducing a one-year paid maternity leave policy (PML). Mothers are entitled to enjoy the paid maternity leave if they were working in the period prior to the child's arrival. The paid maternity leave policy has the following two features. First, maternity leave provides job protection and so mothers are entitled to return to their previous job at the end of the period of leave. ${ }^{28} \mathrm{We}$ approximate the benefit of this by assuming that there is no human capital depreciation when on maternity leave. Second, women on maternity leave receive a cash benefit equal to $69 \%$ of their corresponding wage if they were at work. As we discussed in section 3, this is intended to mimic the generosity of a Scandinavian-style maternity policy in terms of generosity over a year.

Our analysis of this change is partial equilibrium. We might expect there to be general equilibrium effects on wages to the extent that labour supply changes, and there may also be effects through the method of financing the programme. Some of these channels are explored in Erosa et al. (2010). In this paper we focus on the direct effects to highlight the difference caused by the various aspects of reform.

In section 5.1 we provide an overall assessment of the effects of the policy on employment and wages, whereas in section 5.2 we decompose the total effect and analyze separately the two components of the policy.

\subsection{The overall effect}

We report the results in Table 3 and additional details in Tables 4 and 5. We define the "employment rate" as the fraction of women who are either actually "in work" or on maternity leave with the option to return. The overall female employment rate increases from 0.69 to 0.73 . The change in mothers' labour supply is the driving force. Mothers of children aged 0 to 2 increase their employment rate from 0.54 to 0.78 . However, only 0.48 of those mothers are in work; other mothers are on maternity leave. The fraction of mothers of children 0 to 2 in work decreases as a result of the policy because mothers do not have to be in work to protect their future job options. Mothers of children aged 3 to 5 are more likely to be employed after the implementation of the policy: their employment rate goes from 0.70 in the benchmark economy to 0.74 . This is driven by two factors: first, higher attachment to the labour market before childbirth encourages mothers to stay in the labour market afterwards. Second, job protection during leave prevents human capital from depreciating and makes mothers more likely to participate after the first year of having a child. Finally, by the time children reach age 6, there is no difference in the 
Table 3 Policy evaluation: overview

\begin{tabular}{|c|c|c|c|}
\hline & \multicolumn{2}{|c|}{ Simulations: } & \multirow{3}{*}{$\begin{array}{c}\text { Data: } \\
\text { Scandinavian } \\
\text { countries }\end{array}$} \\
\hline & US & US under & \\
\hline & Benchmark & $69 \%$ PML & \\
\hline Female employment rate & 0.69 & 0.73 & 0.82 \\
\hline Mothers 0 to 2 employment rate & 0.54 & 0.78 & 0.72 \\
\hline Mothers 0 to 2 in work & 0.54 & 0.48 & 0.48 \\
\hline Mothers 3 to 5 employment rate & 0.70 & 0.74 & 0.79 \\
\hline Mothers 6 to 14 employment rate & 0.78 & 0.78 & 0.79 \\
\hline Wage gender gap & 0.20 & 0.21 & 0.12 \\
\hline Motherhood wage penalty & 0.06 & 0.08 & - \\
\hline
\end{tabular}

participation rates of mothers: the impact of maternity leave does not lead to permanent increases. $^{29}$

In terms of wages, the wage gender gap goes from 0.20 in the benchmark economy to 0.21 percentage points. There are three important effects operating in opposing directions. First, greater attachment to the labour market during child-bearing reduces the wage gender gap through women having higher human capital. Second, offsetting the first effect, is that in spite of job-protection during maternity leave, there is no accumulation of human capital while on leave, and so the fraction of women who are actually in work and accumulating human capital declines. Finally, as more women participate in the labour market, there is a standard selection effect: new entrants are less productive. This is consistent with empirical evidence of positive self-selection of women into the labour market found in Olivetti and Petrongolo (2008). The second and third effects go in the direction of increasing the wage gender gap, and in our simulations they dominate the first effect. The motherhood wage penalty also worsens from 0.06 to $0.08 .^{30}$ It is worth emphasising that the negative effects on wages of the policy do not imply that the policy reduces welfare or is damaging: the very fact that these selection effects are present shows that the policy has a number of effects that it is designed to have. In particular, the policy keeps more women in the labour force, even if of low productivity, and so generates more independence; and further, the policy allows women to choose to take some time out of work without paying such a severe penalty. These are welfare increasing effects despite the negative wage implications.

In Table 4 we breakdown the effects of the policy on young and older mothers and show how the effects change with the age of the children. The first effect is that participation in the period prior to child birth goes up, and this is particularly so for second children:

Table 4 Policy evaluation: details

\begin{tabular}{llc}
\hline & Base & $69 \%$ PML \\
\hline Participation before 1st child, $Y$ & 0.96 & 1.0 \\
Participation before 1st child, O & 0.90 & 1.0 \\
Participation before 2nd child,, & 0.44 & 0.79 \\
Participation before 2nd child, O & 0.65 & 0.84 \\
Participation after birth, Y & 0.42 & 0.61 \\
Participation after birth, O & 0.56 & 0.62 \\
Participation 5 years after 2nd child, Y & 0.86 & 0.85 \\
Participation 5 years after 2nd child, O & 0.79 & 0.80 \\
Participation 10 years after 2nd child,, & 0.81 & 0.80 \\
Participation 10 years after 2nd child, O & 0.76 & 0.76 \\
\hline
\end{tabular}

$\mathrm{Y}$ : mothers who are young at childbirth. O: mothers who are older at childbirth. "Participation after birth" is measured in the first year after birth 
Table 5 Policy evaluation: regressions

\begin{tabular}{|c|c|c|c|c|}
\hline & \multicolumn{2}{|c|}{ Employment } & \multicolumn{2}{|c|}{ Log Wage } \\
\hline & Marg.ef. & (P-value) & Coefficient & (P-value) \\
\hline Young mother with pre-school child & -0.555 & $(0.00)$ & 0.101 & $(0.00)$ \\
\hline Older mother with pre-school child & -0.385 & $(0.00)$ & 0.096 & $(0.00)$ \\
\hline Young mother with school-age child & -0.018 & $(0.00)$ & -0.036 & $(0.00)$ \\
\hline Older mother with school-age child & -0.010 & $(0.07)$ & 0.002 & $(0.82)$ \\
\hline Young mother with pre-school child*Policy & 0.190 & $(0.00)$ & -0.074 & $(0.00)$ \\
\hline Older mother with pre-school child*Policy & 0.138 & $(0.00)$ & -0.088 & $(0.00)$ \\
\hline Young mother with school-age child*Policy & -0.005 & $(0.48)$ & 0.0064 & $(0.457)$ \\
\hline Older mother with school-age child*Policy & 0.001 & $(0.86)$ & -0.010 & $(0.249)$ \\
\hline Age & -0.040 & $(0.00)$ & 0.048 & $(0.00)$ \\
\hline Age2 & 0.0003 & $(0.00)$ & -0.0005 & $(0.00)$ \\
\hline
\end{tabular}

Pre-school children are 5 and under. School-age children are 6 and over

participation before the second child is born goes from 0.44 to 0.79 , in the case of young mothers, and from 0.65 to 0.84 in the case of older mothers. Older mothers start with higher levels of participation because they typically have more to lose from being out of employment due to their greater human capital accumulation. As noted by Ruhm (1998), women are much more likely to participate in the labour market in order to be eligible for maternity leave benefits. In the case of the arrival of a second child, higher human capital due to the already increased labour market attachment reinforces the direct effect of women participating in order to be eligible for the second maternity leave.

The second effect is that mothers are more likely to return to work in the period right after the second spell of maternity leave. Participation goes up from 0.42 to 0.61 in the case of young mothers and from 0.56 to 0.62 in the case of older mothers. Young mothers are more elastic than older mothers partly because young mothers face a longer horizon to enjoy the returns to accumulated human capital (Imai and Keane 2004) and partly because for young mothers the amount of uncertainty that remains to be resolved is larger than for old mothers (see Low 2005). Finally, we provide statistics to assess the long-run effects of the policy, in particular the effect on participation after 5 and 10 years of the second child arrival. The long-run effects on both groups is negligible.

Our results on employment can be reiterated using probit regressions. We report in the first two columns of Table 5 the marginal effects of a probit estimated on the decision of being employed on a pooled (simulated) sample of individuals before and after the policy, dropping those that never have children. ${ }^{31}$ We include dummies for four different groups of women in the economy: young mothers with children 5 and under (pre-school children), young mothers with children aged 6 to 16 (school-age children), old mothers with pre-school children and old mothers with school-age children. The reference group are mothers with children older than 16. In addition, we include as regressors the four group dummies interacted with the policy and age and age squared. As expected, mothers of pre-school children work less than the reference group, especially in the case of young mothers. The effect of the policy is larger for this group of women, with the employment rate going up by 19.0 percentage points as a result of the policy, in contrast to 13.8 for the group of old mothers with pre-school children. The effect of the policy on mothers of school-age children is not significant.

The third and fourth columns of Table 5 show the effect of the policy on wages. The effects are negative, but modest. The policy has a significant negative effect on the wages 
of mothers of young children, but it has no significant effect on the wages of mothers of children older than 5. As explained above, this is the effect of self-selection into the labour market. This negative effect of the policy on observed wages arises even in the absence of employers being able to change their wage policy with respect to women.

\subsection{Decomposing job protection vs income replacement}

There are two aspects of the maternity leave policy: job protection and income replacement. In this section, in Table 6, we show the effect of each aspect of the policy in isolation. The first column reports the benchmark with no maternity leave policy. The second column reports the effect of maternity leave that only provides job protection, the third column shows the effect of maternity leave policy with $69 \%$ income replacement, but without job protection. Finally, the fourth column shows the effect of job-protection combined with income replacement (the total effect of the policy).

The effect of job protection alone is substantial: it increases employment rates of mothers of young children from $54 \%$ to $70 \%$. The wage gender gap and motherhood wage penalty are not affected by job protection alone. However, the wages of the employed do decline somewhat with job protection due to the selection effects and because women on leave do not accumulate human capital.

Income replacement is less important in our model: the number of those who are actually working falls because of the income effect and the overall rise in those who are employed is small. The wage gender gap and the motherhood wage penalty are eroded much more under the income replacement policy: human capital is not protected from depreciation, and this has important negative effects on wages of the employed, reinforced by the greater number of women who stop work due to the income effect. The income replacement aspect of the policy does not help to increase the small long-run effects of the policy on the employment rate of mothers of children older than 3.

When both aspects of the policy are combined, the overall selection effect means average wage decreases by $2.0 \%$ with respect to the benchmark, $4.0 \%$ in the case of women aged 25 to 34 and $0.4 \%$ in the case of women aged 45 to 54 . This is simular to the decrease of wages estimated by Ruhm (1998) of $2.7 \%$.

\subsection{The effect of the policy under borrowing constraints}

In this section we explore the effect of the policy under the assumption that households cannot borrow against their future income. ${ }^{32}$ In principle, the importance of the

Table 6 Policy evaluation: decomposition

\begin{tabular}{lcccc}
\hline & Base & Job-prot & Inc-Repl & $69 \% \mathrm{PML}$ \\
\hline Female employment rate & 0.69 & 0.72 & 0.68 & 0.73 \\
Mothers 0 to 2 employment rate & 0.54 & 0.70 & 0.60 & 0.78 \\
Mothers 0 to 2 in work & 0.54 & 0.53 & 0.42 & 0.48 \\
Mothers 3 to 5 employment rate & 0.70 & 0.74 & 0.64 & 0.74 \\
Mothers 6 to 14 employment rate & 0.78 & 0.79 & 0.75 & 0.78 \\
Wage gender gap & 0.20 & 0.20 & 0.23 & 0.21 \\
Motherhood wage penalty & 0.06 & 0.06 & 0.11 & 0.08 \\
\hline$\Delta$ observed wage, all women & & $-0.7 \%$ & $-3.8 \%$ & $-2.0 \%$ \\
$\Delta$ observed wage, women 25-34 & & $-2.0 \%$ & $-3.1 \%$ & $-4.0 \%$ \\
$\Delta$ observed wage, women 45-54 & & $-0.6 \%$ & $-0.4 \%$ \\
\hline The $\Delta$ observed wage is the difference between the benchmarkand the experiment
\end{tabular}

The $\Delta$ observed wage is the difference between the benchmark and the experiment 
income replacement may be underestimated in our benchmark economy above because households are allowed to borrow in order to smooth the effect of child care costs or spells out of the labour market on consumption after child arrival.

Table 7 shows that increasing generosity of maternity leave still has a substantial effect and that the main source of that effect is through job protection. There are two reasons for this: first, in the benchmark, only $14 \%$ of households are in debt when the first child arrives; second, the arrival of children is fully anticipated, and so in the presence of the liquidity constraint, households adjust their consumption in anticipation of their needs when the children are young. This would of course be affected if households could not save either, but that seems unrealistic. The provision of income replacement alone does have a larger negative effect on work when households are credit constrained. This is because the borrowing can no longer be used to to smooth consumption and income replacement through maternity leave fulfills this role. However, the job protection effect has a somewhat larger impact in the opposite direction than in the benchmark, and so, overall, the policy has similar effects. In other words, the policy does have larger effects when credit constraints are present, though these are offsetting.

\section{Conclusions}

The focus of this paper has been to assess the role of the different aspects of maternity leave policies. In particular, we focus on the effects of introducing into the US a Scandinavian-style maternity leave policy with both job protection and income replacement. We use a quantitative model of the female labour supply and savings decisions of households calibrated to the US economy. We find that there is a substantial effect on the labour supply of mothers of young children, in particular of mothers of children aged 0 to 5. The employment rate of mothers of children aged 0 to 2 in the US increases to a similar level to that across Scandinavia. We find that the job-protection aspect of the policy is responsible for the increase in participation of mothers of children aged 3 to 5 . In contrast, the income replacement aspect has a negative impact on the participation of this group of women The impact of the policy on wages is modest and negative: it goes in the direction of reducing the average observed wage for mothers relative to men. This is because of selection effects, with maternity leave inducing less productive women to participate as well as encouraging women to take longer periods of leave. These results showing that more generous family policies do not help the gender gap are consistent with the reduced form evidence of Gupta et al. (2008) and Ejrnæs and Kunze (2013). In terms of persistence, the effects on participation and wages disappear by the time children reach age 6 .

Table 7 Policy evaluation under borrowing constrains: decomposition

\begin{tabular}{lcccc}
\hline & Base & Job-prot & Inc-Repl & $69 \%$ PML \\
\hline Female employment rate & 0.68 & 0.71 & 0.67 & 0.72 \\
Mothers 0 to 2 employment rate & 0.54 & 0.72 & 0.62 & 0.78 \\
Mothers 0 to 2 in work & 0.54 & 0.56 & 0.38 & 0.47 \\
Mothers 3 to 5 employment rate & 0.70 & 0.74 & 0.64 & 0.73 \\
Mothers 6 to 14 employment rate & 0.76 & 0.77 & 0.74 & 0.76 \\
Wage gender gap & 0.19 & 0.19 & 0.23 & 0.21 \\
Motherhood wage penalty & 0.06 & 0.05 & 0.13 & 0.08 \\
$\Delta$ observed wage, all women & & $-0.2 \%$ & $-5.2 \%$ & $-2.6 \%$ \\
$\Delta$ observed wage, women 25-34 & & $-2.1 \%$ & $-5.1 \%$ & $-5.1 \%$ \\
$\Delta$ observed wage, women 45-54 & & $+1.4 \%$ & $-5.1 \%$ & $-0.8 \%$ \\
\hline
\end{tabular}


We leave two potentially important considerations for future analysis. First, we have not modelled the effect on employers hiring and remuneration policies. Costs of the policy to the employer may include direct costs if cash benefits to mothers on leave are not funded by the government as well as indirect costs from having to search for a temporary worker to replace the mother on leave. This may have implications for mothers' wages and their probability of being hired before having children. The second consideration is that we have not allowed for general equilibrium effects. To the extent that employment and wage effects are concentrated on women with children of pre-school age, there are unlikely to be widespread general equilibrium consequences. Ignoring general equilibrium effects in this way is plausible to the extent that all workers are substitutable, and so the size of the change to the total number of workers is small.

\section{Endnotes}

${ }^{1}$ We focus on leave taken by the mother and the implications for women.

${ }^{2}$ Jacobsen and Levine (1995) document the negative impact on female earnings due to intermittent labour supply and find evidence that differences in labour market experience between mothers and childless women are key to account for motherhood wage penalties. In line with their findings, Waldfogel (1998b) and Budig and England (2001) find that about $30 \%$ of the motherhood wage penalty is accounted by women's lower levels of work experience. Gupta and Smith (2002) find that after controlling for unobserved heterogeneity, the negative effect of children on mothers' wages disappears.

${ }^{3}$ Rønsen and Sundström (2002) study employment patterns after first and second birth in Finland, Norway and Sweden during the period 1972-92. They find that women who are entitled to a paid leave have a much higher overall employment entry rate during the first 3 years following birth than non-eligible women. The higher entry rates are concentrated mainly in the period after leave expiry.

${ }^{4}$ These effects are in addition to the direct effect that those on maternity leave are counted as being employed.

${ }^{5}$ There are other implications of maternity leave. For example, Dahl et al. (2013) study the effect of the expansion of paid leave in Norway from 18 to 35 weeks without changing the length of job protection. The reform increased the amount of time spent at home versus work by roughly the increased number of weeks allowed. More broadly, they found that the expansions had little effect on children's school outcomes, parental earnings and participation in the labour market in the short or long run, completed fertility, marriage or divorce.

${ }^{6}$ Under the Family and Medical Leave Act, firms employing at least 50 persons within 75 miles of the work site are required to offer eligible workers 12 weeks of job protected but unpaid time off work to care for newborn or newly adopted children.

${ }^{7}$ This contrasts starkly with the results for other state family leave laws (most of which extend rights to unpaid leave beyond those in the 1993 Family and Medical Leave Act, where the estimated effects are much larger for college-educated and married women than for their less advantaged counterparts (Han et al. (2009)).

${ }^{8}$ Some of the leave that mothers take is explicitly maternity leave and some of it is parental leave that could be shared. In reality, parental leave in Scandinavia is increasingly being used by men as well as women. We focus our analysis on the leave enjoyed by mothers and attribute fungible parental leave to the mother. The data comes from OECD Family Database: PF2.1:Key characteristics of parental leave systems (2011). See www.oecd.org/els/soc/PF2_1_Parental_leave_systems.pdf.

${ }^{9}$ This is an alternative to the full rate equivalent used by the OECD (2012). Across countries there is substantial variation in the duration and generosity of maternity leave 
and so, in order to make policies comparable across countries, the OECD calculates the duration of the full-time equivalent of the leave period if paid at $100 \%$ of an employee's last earnings. This is the Full Rate Equivalent (FRE). The average duration of FRE in the OECD is 12.8 weeks. While mothers across Scandinavia enjoy almost 40 weeks of FRE maternity leave, in the US mothers are not entitled to any paid leave.

${ }^{10}$ In principle, all women on maternity or on statutory paid parental leave (legal or contractual) are counted as employed. EU-guidelines stipulate counting parents on parental leave as employees absent for other reasons: they should be counted as employed if the period of absence is less than 3 months or if they continue to receive a significant portion of their previous earnings (at least 50\%).

${ }^{11}$ We take the average of Sweden, Norway and Denmark. See Appendix 1 for the statistics for each country. In the case of Norway, maternal employment rates are not available in the OECD Family Database, so we obtain them from the EU-Survey of Income and Living Conditions.

${ }^{12}$ There are two additional notes here. First, in the US the fraction of single mothers is about 5 points higher than in the Scandinavian countries. However, since the employment rate of single mothers is only 4 percentage points lower than that of married mothers, this can only partially account for the differences in mothers, employment rate that we report here. Second, in the US the divorce rate is slightly higher than across the Scandinavian countries. To the extent that divorce leads to women working more, we would expect to see an even larger employment gap between these countries if women in the US were facing the same divorce risk as the Scandinavian countries.

${ }^{13}$ This is partly the result of differences in state provided child care subsidies.

${ }^{14}$ One of the problems with making these comparisons is that there is substantial variation within the US and across Scandinavia. The reported approximation is taken from the OECD: www.oecd.org/els/soc/PF_1_3_Family_Cash_Benefits_Jul2013.pdf

${ }^{15}$ This is obviously a simplifying assumption since women may qualify for their own pension. However, according to the Social Security System in the US, women can always choose between the maximum of her pension and up to $50 \%$ of her husband pension, and then a spousal benefit is guaranteed even if the woman did not work at all before the full retirement age.

${ }^{16}$ Keeping track of eligibility requires us to introduce an additional state variable, but this state variable is only relevant at the point that the child arrives.

${ }^{17}$ Couch and Placzek (2010) estimated earnings reductions of more than $30 \%$ at the time of job loss and about 12 to $15 \% 6$ years later.

${ }^{18}$ In Scandinavia, there is some evidence that men have changed their working patterns following the increased take-up of maternity leave. We ignore that channel in this paper.

${ }^{19}$ Waldfogel (1998b) finds little difference in early wages between childless women at the age of 21 and childless at 30 and those childless at the age of 21, but mothers at 30 . On the other hand, if fertility is negatively correlated with productivity, our model might underestimate the negative selection effects associated with generous maternity leave.

${ }^{20}$ See OECD family database Chart SF2.5B Definitive childlessness. Chart SF2.3.A: Mean age of women at the birth of the first child.

${ }^{21}$ We assume 3 years between births, consistent with NLSY79 and Natality Detail Files, see Buckles and Munnich (2012).

${ }^{22}$ See Child Care Aware of America (2012).

${ }^{23}$ NLSY79 follows a sample of the cohort of individuals born between 1957 and 1964 . See https://www.nlsinfo.org/content/cohorts/nlsy79.

${ }^{24}$ Hyslop (2001) assumes a different process for wages, as he includes individual fixed effects in the process for female wages, rather than persistent innovation.

${ }^{25}$ Waldfogel uses data from NLSY-YW. She considers an early and a late wage separated on average by about 8 years. 
${ }^{26}$ Budig and England (2001) find that there is a penalty of about $12 \%$ that is due to differences in human capital and education. Anderson et al. (2002) find that the penalty is higher among non-college women.

${ }^{27}$ Note that in our model there are no other possible sources of differences in wages between mothers and childless women besides differences in labour market experience. Furthermore, motherhood is an exogenous state in our model. So it would not make sense to target the gross motherhood wage gap here.

${ }^{28}$ By returning to their existing job, women are able to preserve the firm specific human capital that they had accumulated, even though they do not accumulate any additional human capital while on leave. While there may be some loss to human capital, we assume that the cost is very small compared to the loss of wages and difficulty of trying to find a new job.

${ }^{29}$ There are other dimensions in which the participation decision might be affected: in particular, through part-time work and through changes in the sector that individuals work in, as explored in Nielsen et al. (2004). The incidence of part-time work in the US is smaller than in Scandinavian countries, but it is not obvious why. In principle, we might expect that the lack of maternity leave policy in the US would mean women would want to keep attached to the labour market through part-time jobs. Introducing this into the model would require identifying the source of returns to experience: participation or hours; as well as requiring the inclusion of an additional margin of adjustment: intensive labour supply decision.

${ }^{30}$ According to empirical evidence, a fraction of the motherhood wage penalty is due to women self-selecting into family-friendly occupations. It is unlikely that the maternity leave policy we evaluate here had an effect on this self-selection because, in general, mothers required flexibility for periods longer than the 1 year covered by this policy.

${ }^{31}$ Note that in our simulations we observe the whole life-cycle employment profile of women before and after the policy.

${ }^{32}$ We recalibrate model parameters to match the same statistics as in the benchmark economy.

${ }^{33}$ In principle, we could test whether this unique reservation asset stock property held empirically. However, such a test would be difficult given the quality of asset data. Further, a rejection in the data may well be generated by unobserved heterogeneity which would not be a problem in our solution, where the solution is carried out separately for each type of person.

\section{Appendix 1: Data}

In the main text, we present statistics for Scandinavia by averaging across Denmark, Sweden and Norway. This hides heterogeneity across these countries, and so we present here the disaggregated numbers.

Table 8 Employment rate of mothers by children's age

\begin{tabular}{lccc}
\hline & $\leq 2$ & $3-5$ & $6-14$ \\
\hline Denmark & 0.71 & 0.78 & 0.76 \\
Sweden & 0.72 & 0.81 & 0.76 \\
Norway & 0.74 & 0.78 & 0.85 \\
\hline & & For mothers with children $\leq 2:$ & Total \\
\hline Denmark & In-work & On leave & 0.71 \\
Sweden & 0.51 & 0.20 & 0.72 \\
Norway & 0.45 & 0.27 & 0.74 \\
\hline Source: OECD Family Database & - & - &
\end{tabular}


Table 9 Wage gender gap and fertility rate

\begin{tabular}{lcc}
\hline & Wage Gender Gap & Fertility Rate \\
\hline Denmark & 0.12 & 1.88 \\
Sweden & 0.15 & 1.98 \\
Norway & 0.09 & 1.95 \\
\hline
\end{tabular}

Source: OECD Family Database

Table 10 Other family policies

\begin{tabular}{lcc}
\hline & Child care fee 2-year old to earnings & Annual benefit child 3-12 \\
\hline Denmark & $8 \%$ & 2,306 \\
Sweden & $5 \%$ & 1,865 \\
Norway & $9 \%$ & 1,987 \\
\hline
\end{tabular}

Source: OECD Family Database

\section{Appendix 2: Solution method}

Households have a finite horizon, and so the model is solved numerically by backward recursion from the terminal period. At each age we solve the value function and optimal policy rule, given the current state variables and the solution to the value function in the next period. This approach is standard. The complication in our model arises from the combination of a discrete choice (to participate or not) and a continuous choice (over savings). This combination means that the value function will not necessarily be concave. We briefly describe in this appendix how we deal with this potential non-concavity.

In addition to age, there are four state variables in this problem: the asset stock, the permanent component of earnings of the husband, $v_{t}^{m}$, the permanent component of earnings of the wife, $v_{t}$, and the experience level of the wife. We discretise both earnings variables and the experience level, leaving the asset stock as the only continuous state variable. Since both permanent components of earnings are non-stationary, we are able to approximate this by a stationary, discrete process only because of the finite horizon of the process. We select the nodes to match the paths of the mean shock and the unconditional variance over the life-cycle. In particular, the unconditional variance of the permanent component must increase linearly with age, with the slope given by the conditional variance of the permanent shock. Value functions are increasing in assets $A_{t}$, but they are not necessarily concave, even if we condition on the labour market status in $t$. The nonconcavity arises because of changes in labour market status in future periods: the slope of the value function is given by the marginal utility of consumption, but this is not monotonic in the asset stock because consumption can decline as assets increase and expected labour market status in future periods changes. By contrast, in Danforth (1979) employment is an absorbing state and so the conditional value function will be concave. Under certainty, the number of kinks in the conditional value function is given by the number of periods of life remaining. If there is enough uncertainty, then changes in work status in the future will be smoothed out, leaving the expected value function concave: whether or not an individual will work in $t+1$ at a given $A_{t}$ depends on the realisation of shocks in $t+1$. Using uncertainty to avoid non-concavities is analogous to the use of lotteries elsewhere in the literature.

The choice of participation status in $t$ is determined by the maximum of the conditional value functions in $t$. In our solution, we impose and check restrictions on this participation choice. In particular, we use the restriction that the participation decision switches 
only once as assets increase, conditional on permanent earnings and experience. When this restriction holds, it allows us to interpolate behaviour across the asset grid without losing our ability to determine participation status. We therefore define a reservation asset stock, $R_{t}$, to separate the value function and the choice of consumption made when participating from the value function and choice of consumption made when not participating.

Solving for the reservation asset stock serves two purposes: one, it makes it easier to allow for the fixed cost in the budget constraint in the solution (rather than having an unconditional policy function with a discontinuity); two, it provides an additional check on our numerical solution: the reservation asset stock should be increasing in the wage rate. A sufficient condition for this to be unique is that the conditional value functions be concave. This is not true in general, as discussed above, but uniqueness can be achieved by having enough uncertainty to make the conditional expected value function concave. Even when the conditional value functions are not concave; however, we can have a unique reservation asset stock, particularly if individuals are impatient enough: impatience means that individuals prefer periods of non-participation to be earlier in the life-cycle, and thereby we avoid indifference about the timing of leisure, which can generate non-uniqueness. ${ }^{33}$

In solving the maximisation problem at a given point in the state space, we use a simple golden search method. We solve the model and do the calibration assuming this process is appropriate and assuming there is a unique reservation asset stock for each point in the state space. We then check that the results in our benchmark case are unaffected when we use a global optimizing routine, simulated annealing, and we do not assume a unique reservation asset stock. It is worth stressing that there are parameter values for which the techniques we used do not work. In particular, the assumption of a unique reservation asset stock fails as the variance of shocks gets sufficiently low and if households have discount rates very close to the interest rate. There are no non-concavities due to borrowing constraints in our model because the only borrowing constraint is generated by the nobankruptcy condition, which is in effect enforced by having infinite marginal utility of consumption at zero consumption.

Competing interests

The IZA Journal of Labor Economics is committed to the IZA Guiding Principles of Research Integrity. The authors declare that they have observed these principles.

\section{Acknowledgments}

Virginia Sánchez-Marcos thanks the Spanish Ministry of Science and Technology for Grant ECO2009-09614 and

RecerCaixa for financial support. We thank Nezih Guner and participants at the VIII REDg Workshop for useful comments. We thank an anonymous referee for helpful comments.

Responsible editor: Pierre Cahuc

\section{Author details}

${ }^{1}$ University of Cambridge, Cambridge, UK. ${ }^{2}$ IFS, London, UK. ${ }^{3}$ Departamento de Economía, Universidad de Cantabria

Avda. de los Castros s/n, 39005 Santander, Spain.

Received: 9 March 2015 Accepted: 28 May 2015

Published online: 24 July 2015

\section{References}

Abowd J, Card D (1989) On the Covariance Structure of Earnings and Hours Changes. Econometrica 57(2):411-455

Albrecht J W Edin, P-A, Sundstrøm M, Vroman SB (1999) Career interruptions and subsequent earnings. J Hum Resour 34(1):294-311

Anderson DJ, Binder M, Krause K (2002) The motherhood wage penalty: which mothers pay it and why? Am Econ Rev 92(2):354-358. Papers and Proceedings

Attanasio O, Weber G (1995) Is Consumption growth consistent with intertemporal optimization? Evidence from the consumer expenditure survey. J Polit Econ 103(6):1121-1157 
Attanasio O, Low H, Sánchez-Marcos V (2008) Explaining changes in female labor supply in a life-cycle model. Am Econ Rev 98:1517-1542

Baker M, Milligan K (2008) How does job-protected maternity leave affect Mothers' employment?. J Labor Econ 26:655-691

Baum CL (2003) The effect of state maternity leave legislation and the 1993 family and medical leave act on employment and wages. Labour Econ 10:573-596

Buckles K, Munnich E (2012) Birth spacing and sibling outcomes. J Hum Resour 47(3):613-642

Budig MJ, England P (2001) The wage penalty for Motherhood. Am Sociol Rev 66(2):204-225

Carroll C, Samwick A (1997) The Nature of Precautionary Wealth. J Monetary Econ 40(1):41-71

Child Care AwareofAmerica (2012) Parents and the high cost of child care: 2012 Report. www.naccrra.org

Couch KA, Placzek DW (2010) Earnings losses of displaced workers revisited. Am Econ Rev 100(1):572-589

Dahl G, Løken K, Mogstad M, Salvanes K (2013) What is the case for paid maternity leave? NBER Working Paper 19595

Danforth JP (1979) On the Role of Consumption and Decreasing Absolute Risk Aversion in the Theory of Job Search. In: Lippman SA, McCall JJ (eds). Studies in the Economics of Search, Amsterdam, North-Holland

Ejrnæs M, Kunze A (2013) Work and wage dynamics around childbirth. Scand J Econ 115(3):856-877

Erosa A, Fuster L, Restuccia D (2010) A general equilibrium analysis of parental leave policies. Rev Econ Dyn 13(4):742-758 Gupta ND, Smith N (2002) Children and career interruptions: the family gap in Denmark. Economica 69:609-629

Gupta DN, Oaxaca R, Smith N (2006) Swimming upstream, floating downstream: comparing women's relative wage progress in the United States and Denmark. Industrial and Labor Relations 59(2):243-266

Gupta ND, Smith N, Verner M (2008) The impact of Nordic countries. Family-friendly policies on employment, wages, and children. Rev Econ Househ 6(1):65-89

Han W-J, Waldfogel J (2003) Parental leave: the impact of recent legislation on parents' leave-taking. Demography 40(1):191-200

Han W-J, Ruhm C, Waldfogel J, Washbrook E (2009) Public policies and women's employment after childbearing. NBER Working Paper No. 14660

Hyslop D (2001) Rising U.S. Earnings Inequality and Family Labor Supply: The Covariance Structure of Intrafamily Earnings. Am Econ Rev 91(4):755-777

Imai S, Keane M (2004) Intertemporal Labor Supply and Human Capital Accumulation. Int Econ Rev 45(2):602-631

Jacobsen J, Levine L (1995) The effects of intermittent labor force attachment on women's earnings. Monthly Labor Rev 118:14-19

Jacobson L, LaLonde R, Sullivan D (1993) Earnings losses of displaced workers. Am Econ Rev 83(4):685-709

Klerman JA, Leibowitz A (1999) Job continuity among new mothers. Demography 36:145-155

Lalive R, Zweimüller J (2009) Does parental leave affect fertility and return-to-work? Evidence from two natural experiments. Q J Econ 124(3):1363-1402

Lalive R, Schlosser A, Steinhauer A, Zweimüller J (2014) Parental leave and mothers' careers: the relative importance of job protection and cash benefits. Rev Econ Stud 81(1):219-265

Low H (2005) Self-insurance in a life-cycle model of labour supply and savings. Rev Econ Dyn 8(4):945-975

Low H, Meghir C, Pistaferri L (2010) Wage risk and employment risk over the life-cycle. Am Econ Rev 100(4):1432-1467

MaCurdy T (1983) A simple scheme for estimating an intertemporal model of labor supply and consumption in the presence of taxes and uncertainty. Int Econ Rev 24:265-289

Mincer J, Olfek H (1982) Interrupted work careers: depreciation and restoration of human capital. J Hum Resour 17:3-24

Nielsen HS, Simonsen M, Verner M (2004) Does the gap in family-friendly policies drive the family gap?. Scand J Econ 106(4):721-744

OECD Family Database (2012) PF2.1:Key characteristics of parental leave systems. www.oecd.org/els/soc/ PF2_1_Parental_leave_systems.pdf

Olivetti C (2006) Changes in Women.s Hours of Market Work: The Effect of Changing Returns to Experience. Rev Econ Dyn 9(4):557-587

Olivetti C, Petrongolo B (2008) Unequal pay or unequal employment? A cross-country analysis of gender gaps. J Labor Econ 26:621-654

Rønsen M, Sundström M (2002) Family policy and after-birth employment among new mothers- a comparison of Finland, Norway and Sweden. Eur J Popul 18:121-152

Rossin-Slater M, Ruhm CJ, Waldfogel J (2011) The effects of California's paid family leave program on mothers' leave-taking and subsequent labor market outcomes. NBER Working Paper No. 17715

Ruhm CJ (1998) The economic consequences of parental leave mandates: lessons from Europe. Q J Econ 112(1):285-317

Schönberg U, Ludsteck J (2011) Expansions in maternity leave coverage and mothers' labor market outcomes after childbirth. J Labor Econ

Waldfogel J (1998a) The family gap for young women in the United States and Britain: can maternity leave make a difference? J Labor Econ 16(3):505-545

Waldfogel, J (1998b) Understanding the Family Gap in pay for women with children. J Econ Perspect 12(1):137-156

Waldfogel J, Higuchi Y, Abe M (1999) Family leave policies and women's retention after childbirth: evidence from the United States, Britain, and Japan. J Popul Econ 12:523-545 